Article

\title{
The Influence of Two-Component Mixtures from Spanish Origanum Oil with Spanish Marjoram Oil or Coriander Oil on Antilisterial Activity and Sensory Quality of a Fresh Cut Vegetable Mixture
}

\author{
Karolina Kraśniewska ${ }^{1, *}$, Olga Kosakowska ${ }^{2}$, Katarzyna Pobiega ${ }^{1} @$ and \\ Małgorzata Gniewosz ${ }^{1}$ (D) \\ 1 Department of Food Biotechnology and Microbiology, Institute of Food Sciences, \\ Warsaw University of Life Sciences-SGGW (WULS-SGGW), Nowoursynowska 159, \\ 02-776 Warsaw, Poland; katarzyna_pobiega@sggw.edu.pl (K.P.); malgorzata_gniewosz@sggw.edu.pl (M.G.) \\ 2 Department of Vegetable and Medicinal Plants, Institute of Horticultural Sciences, \\ Warsaw University of Life Sciences-SGGW (WULS-SGGW), Nowoursynowska 159, 02-776 Warsaw, Poland; \\ olga_kosakowska@sggw.edu.pl \\ * Correspondence: karolina_krasniewska@sggw.edu.pl; Tel.: +48-22-593-76-69
}

Received: 26 October 2020; Accepted: 25 November 2020; Published: 26 November 2020

check for updates

\begin{abstract}
The aim of this study was to evaluate two-component mixtures of essential oils (EOs) in sub-inhibitory concentrations for antilisterial protection of minimally processed vegetables. Spanish origanum oil (SOO), Spanish marjoram oil (SMO) and coriander oil (CO) and a mixture of fresh leafy vegetables with red beet were used. The chemical compositions of selected EOs were analyzed by gas chromatography. Carvacrol was the major component of SOO. The dominant active component of SMO was 1,8-cineole, while the major constituent in $\mathrm{CO}$ was linalool. The study shows that essential oils in combination, namely SOO $+\mathrm{SMO}$ and $\mathrm{SOO}+\mathrm{CO}$ in a $1 / 4 \mathrm{MIC}+1 / 4 \mathrm{MIC}$ (Minimal Inhibitory Concentration), have a synergistic effect against L. monocytogenes. The reduction of L. monocytogenes in vegetable mixtures treated by EOs in these selected combinations after $24 \mathrm{~h}$ of storage was approximately equal to the limit of detection. Furthermore, it was found that the vegetable mixture treated with $\mathrm{SOO}+\mathrm{SMO}$ had the highest-rated sensorial quality and could therefore meet consumer expectations.
\end{abstract}

Keywords: essential oils; antibacterial activity; Listeria monocytogenes; minimally processed vegetables; food safety

\section{Introduction}

Listeriosis caused by Listeria monocytogenes is still a rare disease in humans; however, due to high pathogenicity, the need for hospitalization and high mortality, especially among the elderly, it is one of the most dangerous foodborne diseases [1,2]. In the years 2009-2018, an increase in listeriosis in the EU/EEA was observed [3]. High-risk foods due to the presence of L. monocytogenes include ready-to-eat (RTE) products, particularly RTE smoked and gravad fish, heat-treated meat and soft and semi-soft cheese. Thus far, fruits and vegetables have been classified as "low risk" products [3-7]. However, currently, foodborne outbreak statistics show that there is an increasing trend in fresh-cut produce and associated outbreaks mostly caused by such bacterial agents as Listeria monocytogenes, Salmonella spp. and Escherichia coli O157:H7 [8,9]. Fresh vegetables are foods with a short shelf life, so there is a need to optimize moderate processing and storage $[10,11]$. Among natural preservatives are plant essential oils, which can be used to disinfect minimally processed vegetables [12]. Essential 
oils from spice plants have long been used in the food industry as flavorings in food and drink. Essential oils also have a number of biological activities, including antimicrobial, antioxidant, cytotoxic, anti-inflammatory and insecticidal [13]. Even a small addition of essential oils to minimally processed vegetables can enrich them culinarily. In addition, essential oils with strong antimicrobial activity can improve the microbiological safety of these products [14]. It was found that $0.3 \%$ and $0.5 \%$ cinnamon oil was the most effective against Salmonella enterica serotype Newport on organic leafy greens [15], and marjoram essential oil at $0.5 \%$ concentration showed disinfection capacity of multidrug-resistant Salmonella enterica serovar Schwarzengrund in lettuce [14]. Additionally, oregano oil effectively reduced levels of total mesophilic microorganisms in fresh leaf lettuce and radish sprouts [16]. Tetraclinis articulata essential oils can be used as a potential source of fungicides to protect stored tomatoes from pathogens and saprophytic fungi [17]. However, the disadvantage of essential oils in food production, limiting their widespread use, is the intense odor and taste, not always favorably affecting the sensory characteristics of products. Therefore, in the production of food, essential oils are often used in high dilutions, which in turn may prove ineffective in microbiological food protection. In order to preserve the benefits of using essential oils (culinary and antimicrobial) in the production of low-processed vegetables, combinations of essential oils in reduced concentrations are used, while it is necessary to select such a combination for a specific food product [18]. In the study presented by Lv et al. [19], it was shown that combined selected Eos, e.g., oregano-basil, basil-bergamot, oregano-bergamot and oregano-perilla, were considered antimicrobial agents with higher efficacy compared to EOs used alone. Furthermore, this study also suggested that combinations of EOs could minimize application concentrations and consequently reduce any adverse sensory impact in food.

The purpose of this study was to evaluate the antilisterial efficacy of two-component mixtures of essential oils in sub-inhibitory concentrations in model research and on a mixture of fresh low-processed vegetables and to assess the sensory properties of a mixture of vegetables treated with essential oils and their mixtures.

\section{Materials and Methods}

\subsection{Materials}

Essential oils (EOs): Spanish origanum oil of Thymbra capitata (L.) Cav., coriander oil of Coriandrum sativum L., Spanish marjoram oil of Thymus mastichina (L.) L. from Sigma Aldrich (Darmstadt, Germany). Chemical reagents: dimethylsulfoxide (DMSO) and sodium hypochlorite bought from Chempur (Piekary Ślaskie, Poland), phosphate-buffered saline (PBS), tryptic soybean broth (TSB), tryptic soy agar (TSA), buffered peptone water (BPW) and glycerol from BTL (Łódź, Poland), Palcam Agar plus selective supplement (PA) bought from Merck (Darmstadt, Germany).

Plant materials: fresh endive chicory (Cichorium endivia L.), lettuce (Lactuca sativa L.) and red beet (Beta vulgaris L.) and a commercial mixture of the same cut and ready-to-eat vegetables were purchased at the local store on delivery and stored at $8 \pm 1{ }^{\circ} \mathrm{C}$.

The bacterial strain of Listeria monocytogenes 17/11 (a clinical isolate taken from a patient with listeriosis) was from the National Institute of Public Health in Warsaw (Warsaw, Poland). The strain was stored at $-80{ }^{\circ} \mathrm{C}$ in $25 \%$ glycerol. The frozen strain was transferred to TSA and incubated at $37^{\circ} \mathrm{C}$ for $24 \mathrm{~h}$. Then, the culture was transferred to PBS to reach a population of approximately $1 \times 10^{8} \mathrm{CFU} \mathrm{mL}{ }^{-1}$. The solution was tenfold diluted to $1 \times 10^{7} \mathrm{CFU} \mathrm{mL} \mathrm{m}^{-1}$.

\subsection{GC-FID Analysis}

The quantitative GC-FID (gas chromatograph coupled with a flame ionization detector) analysis was carried out using a Hewlett Packard 6890 gas chromatograph equipped with a flame ionization detector (FID) and capillary, polar column HP 20M $(25 \mathrm{~m} \times 0.32 \mathrm{~mm} \times 0.3 \mu \mathrm{m}$ film thickness). The analysis was performed using the following temperature program: oven temperature isotherm at $60{ }^{\circ} \mathrm{C}$ for $2 \mathrm{~min}$, then it was programmed from 60 to $220^{\circ} \mathrm{C}$ at a rate of $4{ }^{\circ} \mathrm{C}$ per min and held 
isothermal at $220^{\circ} \mathrm{C}$ for $5 \mathrm{~min}$. Injector and detector temperatures were, respectively, at 220 and $260^{\circ} \mathrm{C}$. The carrier gas (He) flow was $1.1 \mathrm{~mL} \mathrm{~min}^{-1}$. The split ratio was 1:500. Manual injection of $0.3 \mu \mathrm{L}$ of essential oil was applied. Component identification was confirmed by comparison of their retention times with those of pure authentic samples and by means of their linear retention indices (RI) relative to the series of $n$-hydrocarbons (C7-C30), under the same operating conditions. RI were compared with those reported in the literature [20]. The percentage composition of the essential oils was computed by the normalization method from the GC peak areas, without the use of correction factors.

\subsection{Determination of the Minimal Inhibitory Concentration (MIC)}

The EOs were dissolved in 10\% DMSO, and then their solutions from $0.05 \%$ to $1.5 \%$ in TSB were prepared. Mixtures of two EOs in TSB were also prepared according to Table 1.

Table 1. Two-component mixtures of essential oils in TSB.

\begin{tabular}{cccc}
\hline $\begin{array}{l}\text { Sub-Inhibited } \\
\text { Concentration }\end{array}$ & SOO + SMO & SOO + CO & CO + SMO \\
\cline { 2 - 4 } & & $\mathbf{( \% )}$ & \\
\hline & $0.05+0.45$ & $0.05+0.2$ & $0.2+0.45$ \\
$1 / 2 \mathrm{MIC}+1 / 2 \mathrm{MIC}$ & $0.05+0.225$ & $0.05+0.1$ & $0.2+0.225$ \\
$1 / 2 \mathrm{MIC}+1 / 4 \mathrm{MIC}$ & $0.05+0.1125$ & $0.05+0.05$ & $0.2+0.1125$ \\
$1 / 2 \mathrm{MIC}+1 / 8 \mathrm{MIC}$ & $0.025+0.45$ & $0.025+0.2$ & $0.1+0.45$ \\
$1 / 4 \mathrm{MIC}+1 / 2 \mathrm{MIC}$ & $0.025+0.225$ & $0.025+0.1$ & $0.1+0.225$ \\
$1 / 4 \mathrm{MIC}+1 / 4 \mathrm{MIC}$ & $0.025+0.1125$ & $0.025+0.05$ & $0.1+0.1125$ \\
$1 / 4 \mathrm{MIC}+1 / 8 \mathrm{MIC}$ & $0.0125+0.45$ & $0.0125+0.2$ & $0.05+0.45$ \\
$1 / 8 \mathrm{MIC}+1 / 2 \mathrm{MIC}$ & $0.0125+0.225$ & $0.0125+0.1$ & $0.05+0.225$ \\
$1 / 8 \mathrm{MIC}+1 / 4 \mathrm{MIC}$ & $0.0125+0.1125$ & $0.0125+0.05$ & $0.05+0.1125$ \\
$1 / 8 \mathrm{MIC}+1 / 8 \mathrm{MIC}$ &
\end{tabular}

TSB-tryptic soy agar, EOs—essential oils, MIC—minimal inhibitory concentration, SOO—Spanish origanum oil, SMO—Spanish marjoram oil, $\mathrm{CO}$-coriander oil.

Next, $380 \mu \mathrm{L}$ of TSB containing EOs separately or mixtures at different concentrations and $20 \mu \mathrm{L}$ of inoculum L. monocytogenes were transferred to wells of a sterile Honeycomb plate (Thermo Scientific, Warsaw, Poland). In each well, the initial number of L. monocytogenes was approximately $5 \times 10^{5} \mathrm{CFU}$ $\mathrm{mL}^{-1}$. Strain growth control was performed in TBS (without EO) with the L. monocytogenes inoculum. The negative control was TBS without EO and bacterial inoculum. The Honeycomb 2 plates were placed on a Bioscreen C apparatus (OY Growth Curves Ab Ltd., Turku, Finland) and incubated at $37^{\circ} \mathrm{C}$ for $24 \mathrm{~h}$. Plates were shaken before measurement and the automatic optical density (OD) was measured at $\lambda 600 \mathrm{~nm}$ every $1 \mathrm{~h}$. A smaller change in OD value than $0.2(\Delta \mathrm{OD}<0.2)$ at the initial and final incubation hours was considered as no test strain growth. The minimum inhibitory concentration (MIC) of the EO or mixture of EOs was defined as the lowest concentration at which there was no growth of the test strain. Three independent series of experiments in triplicate were performed.

Antilisterial activity of EO mixtures was expressed as the fractional inhibitory concentration index (FICI), equal to the sum of fractional inhibitory concentrations (FICs) for each EO, which was calculated according to the following formula [21]:

$$
\mathrm{FICI}=\mathrm{FIC}_{\mathrm{EO} 1}+\mathrm{FIC}_{\mathrm{EO} 2}=\left(\mathrm{MIC}_{\mathrm{EO} 1} \text { in combination } / \mathrm{MIC} \mathrm{EO}_{\mathrm{E} 1} \text { alone }\right)+\left(\mathrm{MIC}_{\mathrm{EO} 2} \text { in combination } / \mathrm{MIC} \mathrm{EO}_{\mathrm{E} 2} \text { alone }\right)
$$

The FIC is calculated by comparing the MIC of each EO alone with the combination-derived MIC. The synergistic effect of EOs in the mixture is at FICI values $\leq 0.5$, nonsynergistic or additive action is at values in the range $1 \geq$ FICI $>0.5$, and FICI values between 1 and 4 indicate a neutral effect. A FICI $>4$ indicates antagonistic activity of EOs in the mixture [22]. 


\subsection{Microbiological Analyses}

\subsubsection{In Vegetable Filtrate}

In total, $200 \mathrm{~g}$ of vegetable mixture in equal proportions of endive chicory, lettuce and red beet was washed under running water and blended with $800 \mathrm{~mL}$ of distilled water and filtered through gauze. Then, the vegetable filtrate was sterilized at $117^{\circ} \mathrm{C}$ for $15 \mathrm{~min}$. Its $\mathrm{pH}$ was 6.27 . Five $20 \mathrm{~mL}$ portions of vegetable filtrate were prepared with EOs in MIC and with two mixtures of $\mathrm{SOO}+\mathrm{CO}$ and $\mathrm{SOO}+\mathrm{SMO}$ at $1 / 4 \mathrm{MIC}+1 / 4 \mathrm{MIC}$ combination. The control sample was $20 \mathrm{~mL}$ of vegetable filtrate without EOs. To the samples with/without EOs, $1 \mathrm{~mL}$ of L. monocytogenes inoculum (prepared as above) was added and the samples were incubated at $37^{\circ} \mathrm{C}$ for $24 \mathrm{~h}$. The cell numbers of $L$. monocytogenes were determined at $0,4,6,12$ and $24 \mathrm{~h}$ in TSA. Plates were incubated at $37^{\circ} \mathrm{C}$ for $24 \mathrm{~h}$. The result was reported in $\mathrm{CFU} \times \mathrm{mL}^{-1}$. Three independent series of experiments in triplicate were performed.

\subsubsection{In a Mixture of Fresh Cut Vegetables}

A $600 \mathrm{~g}$ commercial ready-to-eat mixture of fresh cut vegetables (endive chicory, lettuce and red beet in equal proportions) was first washed under running water, then washed in distilled water and immersed in a solution of $0.05 \%$ sodium hypochlorite for $15 \mathrm{~min}$ to reduce natural microflora. Then, the vegetables were immersed in the inoculum of L. monocytogenes (prepared as above) at room temperature $\left(22^{\circ} \mathrm{C}\right)$ for $15 \mathrm{~min}$. They were air-dried at $22^{\circ} \mathrm{C}$ for $1 \mathrm{~h}$ in the biosafety cabinet for better cell adhesion, with plant tissue and excess fluid removed. The vegetables were aseptically divided into six portions of $50 \mathrm{~g}$, in duplicate, which for $1 \mathrm{~min}$ were immersed in solutions containing SOO, $\mathrm{CO}$ or SMO at MIC $(0.1 \%, 0.4 \%$ and $0.9 \%$, respectively) prepared in phosphate-buffered saline (PBS, $\mathrm{pH} 7.0)$ or mixtures of $\mathrm{SOO}+\mathrm{CO}$ and $\mathrm{SOO}+\mathrm{SMO}$ in a combination at $1 / 4 \mathrm{MIC}+1 / 4 \mathrm{MIC}$, previously diluted in 10\% DMSO. The control sample consisted of inoculated vegetables dipped in sterile distilled water. Thirty minutes after sample preparation, the number of L. monocytogenes was determined. For this purpose, $25 \mathrm{~g}$ samples were transferred to $225 \mathrm{~mL}$ of BPW and homogenized in a stomacher (Lab-Blender 400, Seward Medical, London, UK) for $1 \mathrm{~min}$. All samples were diluted ten-fold and transferred in duplicate into PA. Plates were incubated at $37^{\circ} \mathrm{C}$ for $24 \mathrm{~h}$. Three independent series of experiments in triplicate were performed.

\subsection{Sensory Evaluation}

A commercial ready-to-eat mixture of vegetables (described above) was used. The vegetables were soaked in solutions of EOs prepared in phosphate-buffered saline (PBS, pH 7.0). The solutions contained EOs alone at MIC, i.e., $0.1 \% \mathrm{SOO}, 0.4 \% \mathrm{CO}, 0.9 \% \mathrm{SMO}$, or mixtures of $\mathrm{SOO}+\mathrm{CO}$ and $\mathrm{SOO}+$ $\mathrm{SMO}$ at $1 / 4 \mathrm{MIC}+1 / 4 \mathrm{MIC}$, previously diluted in $10 \% \mathrm{DMSO}$. The vegetables were incubated in solutions for $1 \mathrm{~min}$, after which they were dried and stored in sterile plastic containers at $8 \pm 1{ }^{\circ} \mathrm{C}$ and $55 \%-60 \%$ relative humidity in a cooling incubator (CHL5, Pol-Eko-Aparatura, Wodzisław, Poland) for 4 days. All samples were evaluated after $30 \mathrm{~min}$ and after 4 days of refrigerated storage. The sensory evaluation of vegetables was performed by a team of 50 partially trained panelists, consisting of employees and students of the Institute of Food Sciences, WULS-SGGW in Warsaw, using a nine-point hedonic scale in accordance with the methodology described by Baryłko-Pikielna and Matuszewska [23]. Samples of $10 \mathrm{~g}$ were coded with random numbers and given in randomized duplicates. The panelists used a list of qualitative descriptors established at a special session, i.e., color, texture, odor, taste and overall quality, which is a summary of the features included in the assessment. The intensity of each descriptor was assessed on a continuous graphic scale, with edge markings, where 1 represents extremely dislike and 9 represents extremely like. Average values were calculated and the results were presented in the form of a chart. 


\subsection{Statistical Analysis}

All the measurements were performed at least in duplicate. One-way ANOVA was used for independent samples. In order to verify the significance of differences between the means, Tukey's test was used at the significance level $\alpha=0.05$. Statistical analysis was performed using Statistica version 10 .

\section{Results}

\subsection{Chemical Composition of Essential Oils}

Table 2 shows the chemical composition of SOO, CO and SMO. Twelve compounds were found in SOO, with the highest percentage of carvacrol $(79.11 \%)$, linalool $(4.14 \%)$ and $p$-cymene $(4.01 \%)$. CO contained 15 compounds and was rich in linalool (68.45\%), $\alpha$-pinene $(6.66 \%)$ and $p$-cymene $(6.14 \%)$. In turn, SMO contained 14 compounds, among which 1,8-cineole $(69.15 \%)$ had the largest share, followed by $\beta$-pinene $(4.73 \%)$ and limonene $(4.09 \%)$. EOs contained only three of the same components: $\alpha$-pinene, $p$-cymene and linalool.

\subsection{Inhibition of L. monocytogenes Growth by Essential Oils}

Figure 1 shows the effect of EOs in concentrations in the range from $0.05 \%$ to $1.5 \%$ on changes in optical density (OD) of L. monocytogenes after $24 \mathrm{~h}$. The essential oils' MIC values for L. monocytogenes varied from $0.1 \%$ to $0.9 \%$. The smallest MIC value was found for SOO $(0.1 \%)$, followed by CO $(0.4 \%)$ and the highest for SMO (MIC 0.9\%).

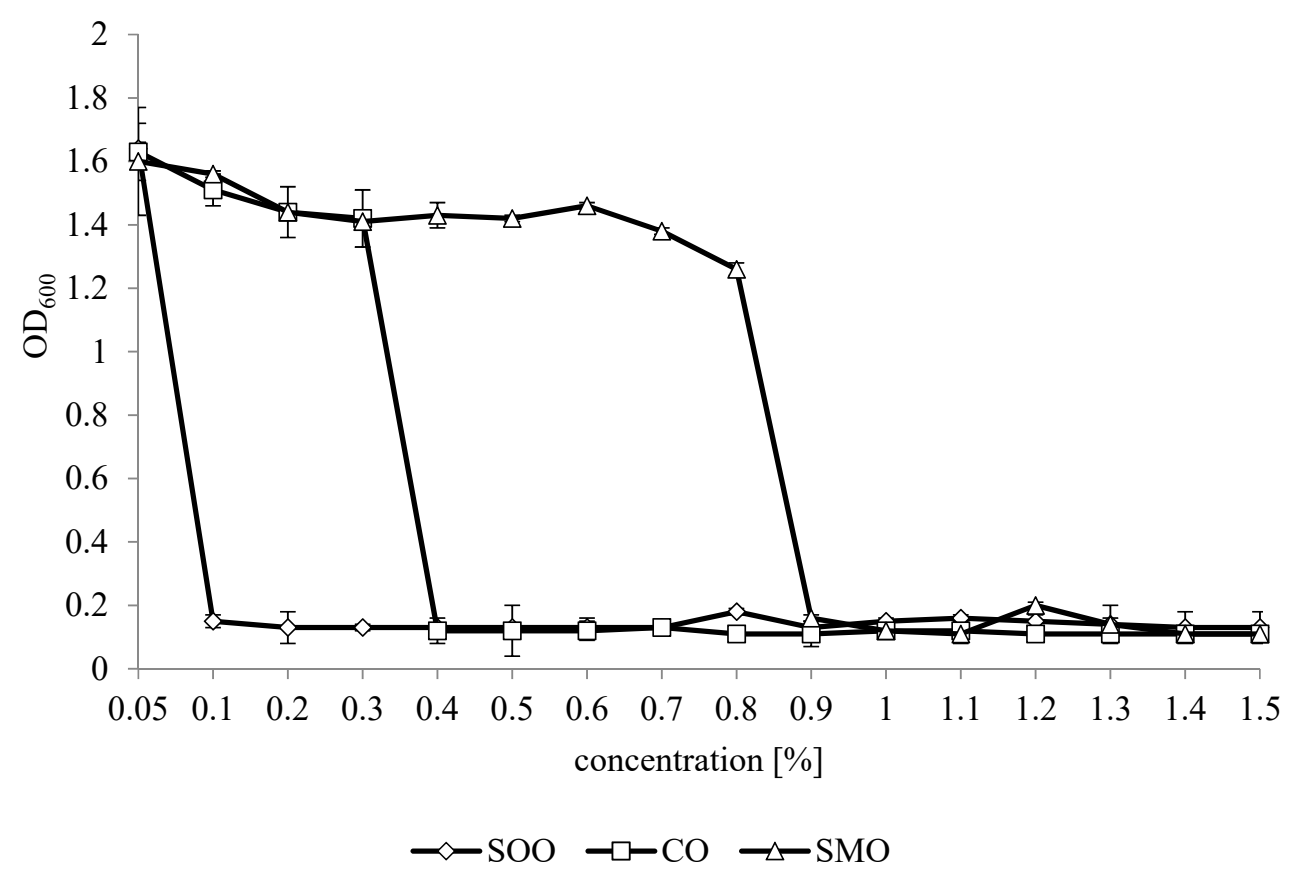

Figure 1. Changes in $\mathrm{OD}_{600}$ for an L. monocytogenes culture with essential oils after $24 \mathrm{~h}$. SOO-Spanish origanum oil, $\mathrm{CO}$ —coriander oil, $\mathrm{SMO} —$ Spanish marjoram oil. 
Table 2. Gas chromatographic composition (\% peak area) of Spanish origanum oil (SOO), coriander oil (CO) and Spanish marjoram oil (SMO) (\% of total).

\begin{tabular}{|c|c|c|c|c|c|c|c|c|c|}
\hline \multirow[t]{2}{*}{ No } & \multicolumn{3}{|c|}{ SOO } & \multicolumn{3}{|c|}{$\mathrm{CO}$} & \multicolumn{3}{|c|}{ SMO } \\
\hline & Compound & RI & $\%$ & Compound & RI & $\%$ & Compound & RI & $\%$ \\
\hline 1 & $\alpha$-Pinene & 1028 & $0.54 \pm 0.15$ & $\alpha$-Pinene & 1028 & $6.66 \pm 0.16$ & $\alpha$-Pinene & 1028 & $3.08 \pm 0.04$ \\
\hline 2 & $\beta$-Myrcene & 1168 & $1.11 \pm 0.00$ & Camphene & 1075 & $1.17 \pm 0.02$ & Camphene & 1075 & $1.35 \pm 0.01$ \\
\hline 4 & $\gamma$-Terpinene & 1249 & $3.44 \pm 0.01$ & Limonene & 1203 & $2.62 \pm 0.04$ & Sabinene & 1124 & $3.95 \pm 0.01$ \\
\hline 5 & $p$-Cymene & 1272 & $4.01 \pm 0.01$ & $\gamma$-Terpinene & 1248 & $0.84 \pm 0.01$ & Limonene & 1203 & $4.09 \pm 0.01$ \\
\hline 6 & Linalool & 1541 & $4.14 \pm 0.00$ & $p$-Cymene & 1272 & $6.14 \pm 0.09$ & 1,8-Cineole & 1209 & $69.15 \pm 0.17$ \\
\hline 7 & Bornyl acetate & 1580 & $0.87 \pm 0.03$ & Geraniol & 1436 & $1.13 \pm 0.01$ & p-Cymene & 1272 & $3.34 \pm 0.02$ \\
\hline 9 & $\alpha$-Terpineol & 1696 & $0.77 \pm 0.06$ & unidentified & & $0.81 \pm 0.01$ & Linalool & 1541 & $1.70 \pm 0.01$ \\
\hline 10 & Geranial & 1730 & $2.79 \pm 0.01$ & unidentified & & $4.79 \pm 0.02$ & Terpinen-4-ol & 1584 & $0.41 \pm 0.008$ \\
\hline 11 & Thymol & 2165 & $0.69 \pm 0.10$ & Linalool & 1541 & $68.45 \pm 0.27$ & $\beta$-Caryophyllene & 1593 & $0.63 \pm 0.008$ \\
\hline 12 & Carvacrol & 2213 & $79.11 \pm 0.64$ & unidentified & & $0.41 \pm 0.01$ & $\alpha$-Terpineol & 1696 & $3.81 \pm 0.08$ \\
\hline 13 & & & & Geranyl acetate & 1751 & $2.77 \pm 0.06$ & Borneol & 1699 & $1.39 \pm 0.01$ \\
\hline 14 & & & & Cirtronellol & 1767 & $0.48 \pm 0.02$ & Caryophyllene oxide & 1955 & $0.67 \pm 0.02$ \\
\hline \multirow[t]{2}{*}{15} & & & & unidentified & & $1.13 \pm 0.04$ & & & \\
\hline & Total identified & & $99.54 \pm 0.56$ & Total identified & & $98.82 \pm 0.58$ & Total identified & & $99.52 \pm 0.28$ \\
\hline
\end{tabular}

RI: retention indices relative, values are means \pm standard deviations $(n=3)$; SOO—Spanish oreganum oil, SMO—Spanish marjoram oil, $\mathrm{CO} —$ coriander oil. 


\subsection{Inhibition of L. monocytogenes Growth by Mixtures of Essential Oils}

The effect of mixtures of two EOs in different combinations and concentrations on inhibition of L. monocytogenes growth is shown in Figure 2. Five SOO $+\mathrm{SMO}$ mixtures showed bacteriostatic activity against L. monocytogenes. These were mixtures of SOO at $1 / 2 \mathrm{MIC}$ in combination with SMO at $1 / 2$ MIC, $1 / 4$ MIC or $1 / 8 \mathrm{MIC}$ and mixtures of SOO at $1 / 4 \mathrm{MIC}$ in combination with SMO at $1 / 2 \mathrm{MIC}$ or $1 / 4$ MIC. Four mixtures of SOO + CO inhibited the growth of L. monocytogenes, in which SOO at $1 / 2 \mathrm{MIC}$ was in combination with $\mathrm{CO}$ at $1 / 2 \mathrm{MIC}$ or $1 / 4 \mathrm{MIC}$ and $\mathrm{SOO}$ at $1 / 4 \mathrm{MIC}$ was in combination with $\mathrm{CO}$ at $1 / 2 \mathrm{MIC}$ or $1 / 4 \mathrm{MIC}$. On the other hand, only two mixtures of $\mathrm{CO}+\mathrm{SMO}$ showed a bacteriostatic effect against $L$. monocytogenes. These were mixtures containing $\mathrm{CO}+\mathrm{SMO}$ in a $1 / 2 \mathrm{MIC}+1 / 2 \mathrm{MIC}$ combination and in a $1 / 2$ MIC + 1/4 MIC combination.
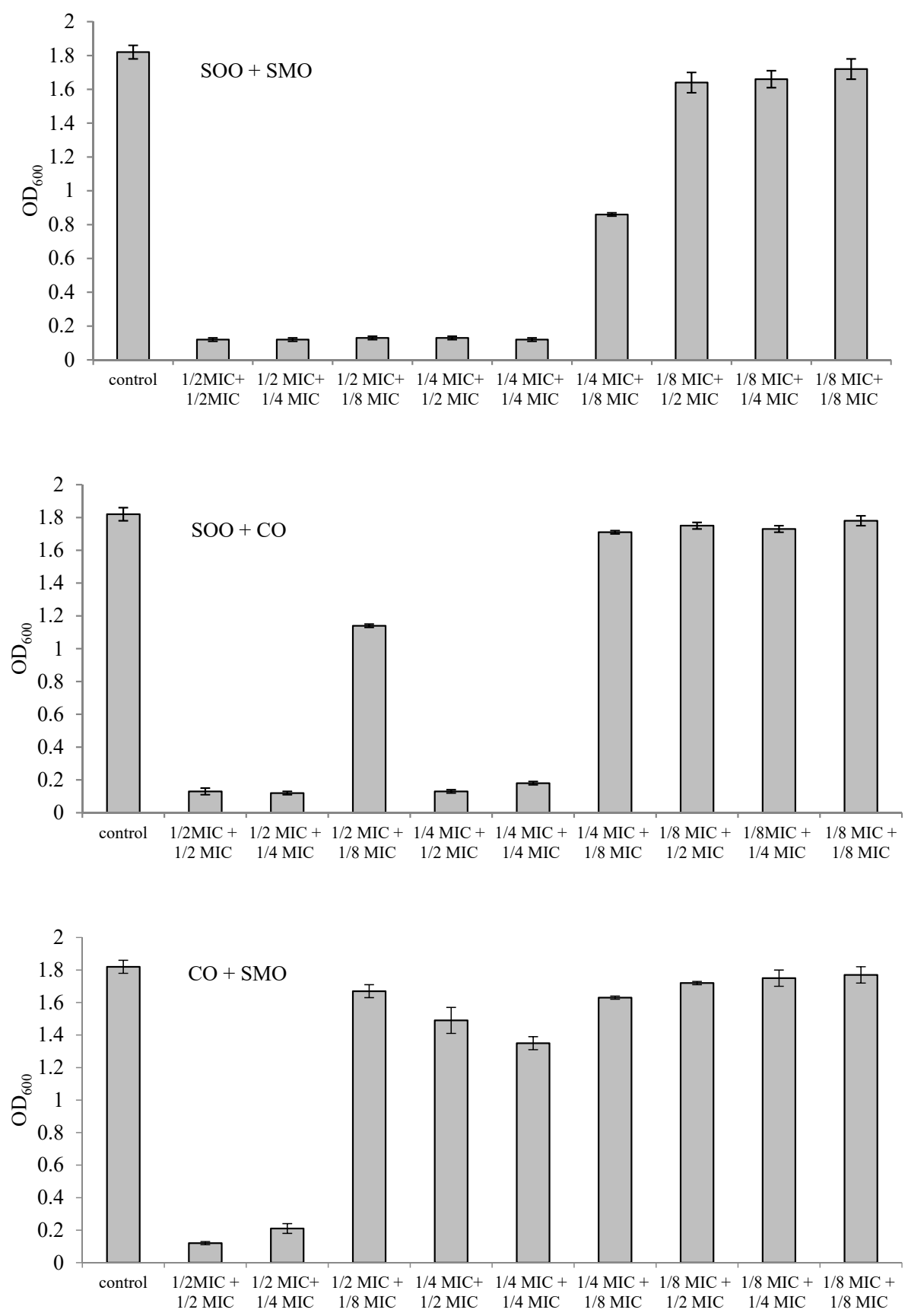

Figure 2. Changes in $\mathrm{OD}_{600}$ for an L. monocytogenes culture with mixtures of essential oils (EOs) after 24 h. SOO—Spanish origanum oil, SMO—Spanish marjoram oil, $\mathrm{CO} —$ coriander oil. 
A FICI value of 0.5 (Table 3) was observed only for two mixtures, $\mathrm{SOO}+\mathrm{SMO}$ and $\mathrm{SOO}+\mathrm{CO}$ in a $1 / 4$ MIC + 1/4 MIC combination, suggesting a synergistic effect of the components of the EOs in these combinations against $L$. monocytogenes. The FICI value of 0.75 revealed the additive effect of $\mathrm{SOO}+$ $\mathrm{SMO}$ and $\mathrm{SOO}+\mathrm{CO}$ in a $1 / 2 \mathrm{MIC}+1 / 4 \mathrm{MIC}$ combination. The $\mathrm{SOO}+\mathrm{SMO}$ mixture in the combination $1 / 2 \mathrm{MIC}+1 / 8 \mathrm{MIC}$ also had an additive effect (FICI 0.625). In turn, the interaction of essential oils in $\mathrm{SOO}+\mathrm{SMO}, \mathrm{SOO}+\mathrm{CO}$ and $\mathrm{CO}+\mathrm{SMO}$ mixtures in a $1 / 2 \mathrm{MIC}+1 / 2 \mathrm{MIC}$ combination was neutral in relation to L. monocytogenes. The combination of $\mathrm{CO}$ and $\mathrm{SMO}$ at sub-inhibitory concentrations $(1 / 4 \mathrm{MIC}+1 / 4 \mathrm{MIC}$ or $1 / 4 \mathrm{MIC}+1 / 8 \mathrm{MIC})$ did not inhibit the growth of L. monocytogenes.

Table 3. Fractional inhibitory concentration index (FICI) values and interactions between combinations of essential oils.

\begin{tabular}{cccccc}
\hline $\begin{array}{c}\text { Mixture of } \\
\text { Essential Oil }\end{array}$ & $\begin{array}{c}1 / 2 \mathrm{MIC}+1 / 2 \\
\text { MIC }\end{array}$ & $\begin{array}{c}1 / 2 \mathrm{MIC}+1 / 4 \\
\text { MIC }\end{array}$ & $\begin{array}{c}1 / 2 \mathrm{MIC}+1 / 8 \\
\text { MIC }\end{array}$ & $\begin{array}{c}1 / 4 \mathrm{MIC}+1 / 2 \\
\text { MIC }\end{array}$ & $\begin{array}{c}1 / 4 \mathrm{MIC}+1 / 4 \\
\text { MIC }\end{array}$ \\
\hline SOO + SMO & $1(\mathrm{I})$ & $0.75(\mathrm{~A})$ & $0.625(\mathrm{~A})$ & $0.75(\mathrm{~A})$ & $0.5(\mathrm{~S})$ \\
$\mathrm{SOO}+\mathrm{CO}$ & $1(\mathrm{I})$ & $0.75(\mathrm{~A})$ & - & $0.75(\mathrm{~A})$ & $0.5(\mathrm{~S})$ \\
$\mathrm{CO}+\mathrm{SMO}$ & $1(\mathrm{I})$ & - & - & $0.75(\mathrm{~A})$ & - \\
\hline MIC-minimal & inhibitory & & - & -
\end{tabular}

MIC-minimal inhibitory concentration; A-addition; I-indifference; S-synergism; —-not detected. SOO—Spanish origanum oil, SMO—Spanish marjoram oil, CO—coriander oil.

\subsection{Inactivation of L. monocytogenes in Vegetable Filtrate and Mixture of Fresh Cut Vegetables with EOs}

The inactivation of L. monocytogenes in the vegetable filtrate with EOs at $1 \mathrm{MIC}$ alone or with the mixtures of EOs at $1 / 4 \mathrm{MIC}+1 / 4 \mathrm{MIC}$ is shown in Table 4 . The initial number of L. monocytogenes in the control was $5.8 \log \mathrm{CFU} \mathrm{mL} \mathrm{m}^{-1}$ and increased by three log cycles after $24 \mathrm{~h}$. The addition to the vegetable filtrate of $\mathrm{SOO}$ at $1 \mathrm{MIC}$ reduced the number of $L$. monocytogenes approximately by five $\log$ cycles after $4 \mathrm{~h}$. CO and SMO at $1 \mathrm{MIC}$ had a weaker antilisterial effect, because it reduced the number of bacteria by 3.5 and $2.3 \log$ cycles after $4 \mathrm{~h}$. In the vegetable filtrate with the addition of EOs alone at $1 \mathrm{MIC}$, it was found that the number of viable L. monocytogenes cells was at the limit of detection $\left(<1 \log \mathrm{CFU} \times \mathrm{mL}^{-1}\right)$ after $24 \mathrm{~h}$.

Table 4. Changes in the number of L. monocytogenes in vegetable filtrate and in mixture of fresh cut vegetables.

\begin{tabular}{|c|c|c|c|c|c|c|}
\hline Time $[\mathrm{h}]$ & Control & $\begin{array}{c}\text { SOO } \\
\text { 1MIC: } 0.1 \%\end{array}$ & $\begin{array}{c}\mathrm{CO} \\
\text { 1MIC: } 0.4 \%\end{array}$ & $\begin{array}{c}\text { SMO } \\
\text { 1MIC: } 0.9 \%\end{array}$ & $\begin{array}{c}1 / 4 \mathrm{MIC} \\
\mathrm{SOO}+1 / 4 \\
\text { MIC CO }\end{array}$ & $\begin{array}{c}1 / 4 \text { MIC } \\
\text { SOO + } 1 / 4 \\
\text { MIC SMO }\end{array}$ \\
\hline \multicolumn{7}{|c|}{ Vegetable filtrate $\left(\log _{10} \mathrm{CFU} \times \mathrm{mL}^{-1}\right)$} \\
\hline 0 & $5.8 \pm 0.4^{\mathrm{a}}$ & $5.9 \pm 0.3^{\mathrm{a}}$ & $5.9 \pm 0.1^{\mathrm{a}}$ & $6.1 \pm 0.1^{\mathrm{a}}$ & $5.9 \pm 0.1^{\mathrm{a}}$ & $6.1 \pm 0.2^{\mathrm{a}}$ \\
\hline 4 & $6.0 \pm 0.1^{\mathrm{e}}$ & $<1.00^{\mathrm{a}}$ & $2.4 \pm 0.3^{c}$ & $3.8 \pm 0.2^{\mathrm{d}}$ & $1.8 \pm 0.1^{b}$ & $2.7 \pm 0.3^{c}$ \\
\hline 6 & $6.5 \pm 0.3^{\mathrm{e}}$ & $<1.00^{\mathrm{a}}$ & $2.2 \pm 0.2^{c}$ & $3.6 \pm 0.1^{\mathrm{d}}$ & $1.5 \pm 0.1^{b}$ & $2.1 \pm 0.1^{\mathrm{c}}$ \\
\hline 12 & $6.7 \pm 0.1^{\mathrm{c}}$ & $<1.00^{\mathrm{a}}$ & $2.0 \pm 0.1^{b}$ & $2.3 \pm 0.1^{b}$ & $<1.00^{\mathrm{a}}$ & $1.9 \pm 0.1^{b}$ \\
\hline 24 & $8.7 \pm 0.2^{b}$ & $<1.00^{\mathrm{a}}$ & $<1.00^{\mathrm{a}}$ & $<1.00^{\mathrm{a}}$ & $<1.00^{\mathrm{a}}$ & $<1.00^{\mathrm{a}}$ \\
\hline \multicolumn{7}{|c|}{ Fresh vegetable $\left(\log _{10} \mathrm{CFU} \times \mathrm{g}\right)$} \\
\hline 0.5 & $6.3 \pm 0.2^{\mathrm{e}}$ & $<1.00^{\mathrm{a}}$ & $3.8 \pm 0.2^{\mathrm{c}}$ & $4.5 \pm 0.2^{\mathrm{d}}$ & $3.0 \pm 0.2^{b}$ & $3.7 \pm 0.2^{c}$ \\
\hline
\end{tabular}

Adding to the vegetable filtrate EO mixtures at sub-inhibitory concentrations significantly $(p<0.05)$ reduced the number of L. monocytogenes after $4 \mathrm{~h}$. However, differences in the potency of the EO mixtures against bacteria were observed. At the same time, the $\mathrm{SOO}+\mathrm{CO}$ mixture resulted in a greater reduction $(p<0.05)$ in the number of cells in the test strain than the $\mathrm{SOO}+\mathrm{SMO}$ mixture at a $1 / 4 \mathrm{MIC}+1 / 4 \mathrm{MIC}$ combination. In the sample with the $\mathrm{SOO}+\mathrm{CO}$ mixture, the number of L. monocytogenes decreased by $3.8 \mathrm{log}$ cycles after $4 \mathrm{~h}$ and this tendency persisted in the remaining time 
interval. No significant differences $(p>0.05)$ were found between L. monocytogenes numbers in the vegetable filtrate treated with the $\mathrm{SOO}+\mathrm{CO}$ mixture and $\mathrm{CO}$ alone for up to $6 \mathrm{~h}$. The $\mathrm{SOO}+\mathrm{SMO}$ mixture had a weaker effect on L. monocytogenes, which reduced the number of cells approximately by three $\log$ cycles after $4 \mathrm{~h}$. After $24 \mathrm{~h}$, the number of L. monocytogenes in the vegetable filtrate containing EO mixtures was $<1 \log \mathrm{CFU} \times \mathrm{mL}^{-1}$.

Treatment of the fresh cut vegetable mixture by EOs or their mixtures resulted in a decrease in the number of L. monocytogenes approximately by three log cycles after $30 \mathrm{~min}$ (Table 4). SOO at $0.1 \%$ (1 MIC) had very strong activity and reduced the number of L. monocytogenes to the limit of detection. Statistically significant differences $(p<0.05)$ were found between bacterial numbers in the CO-treated vegetable mixture at $1 \mathrm{MIC}$ and $\mathrm{SOO}+\mathrm{CO}$, at a $1 / 4 \mathrm{MIC}+1 / 4 \mathrm{MIC}$ combination, which indicates the stronger antilisterial effect of this mixture.

\subsection{Sensory Evaluation of a Mixture of Fresh Cut Vegetables Treated with EOs or EO Mixtures}

The results of sensory analysis of the mixture of vegetables treated with EOs at 1 MIC and their mixtures at a $1 / 4 \mathrm{MIC}+1 / 4 \mathrm{MIC}$ combination are shown in Figure 3 . Treatment of the vegetable mixture with $\mathrm{EOs}$ or $\mathrm{SOO}+\mathrm{CO}$ and $\mathrm{SOO}+\mathrm{SMO}$ mixtures did not have a significant effect $(p>0.05)$ on color or texture, but it statistically $(p<0.05)$ significantly affected the odor, taste and overall quality assessment, which reduced the desirability of these vegetables (Figure 3A). Lower scores for these descriptors were obtained for samples treated by EOs alone than by mixtures of EOs. The sample treated with $\mathrm{SOO}+$ SMO in a $1 / 4$ MIC $+1 / 4$ MIC combination had the highest overall quality. The average scores for all descriptors of this sample did not differ significantly statistically $(p<0.05)$ from the control sample. The CO-treated sample at $1 \mathrm{MIC}$ had the lowest average odor and taste scores, which significantly reduced the desirability of this sample.

A

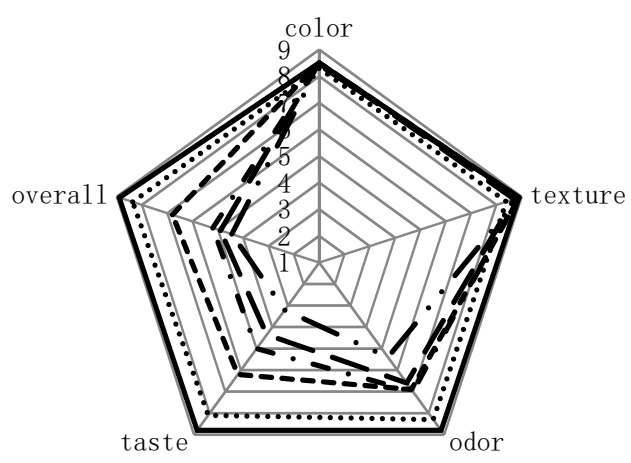

$\mathrm{B}$
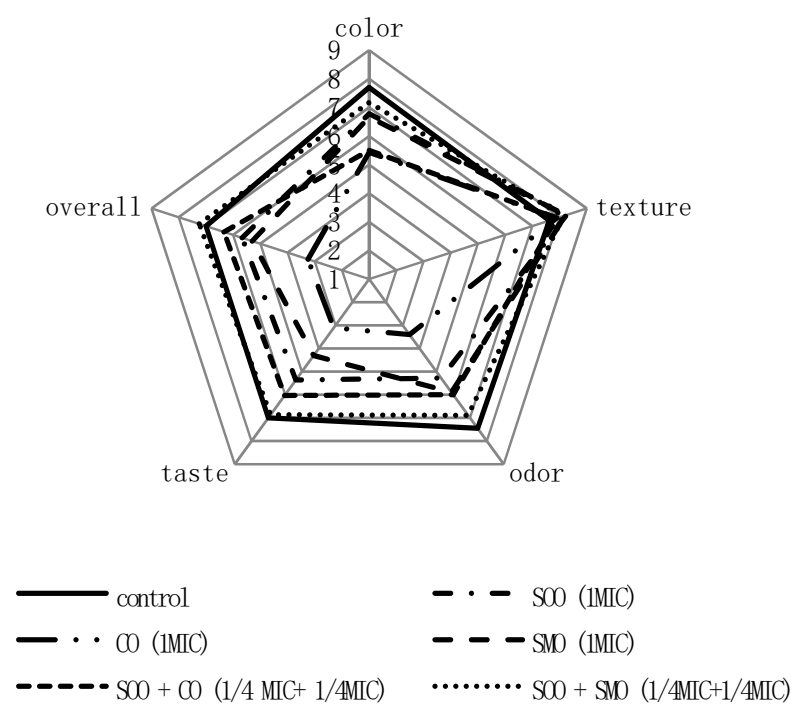

Figure 3. Changes in the sensory quality of a vegetable mixture treated by the addition of EOs or a mixture of EOs (A) after $30 \mathrm{~min}$, (B) after 4 days of storage.

After 4 days of storage, the vegetable mixture quality deteriorated (Figure 3B). Vegetable samples treated with EO mixtures were rated better than EOs alone. The control sample and the sample treated with the SOO + SMO mixture at a $1 / 4$ MIC + 1/4 MIC combination differed the least. Both samples obtained the highest scores, with overall quality of 7.00 and 7.25 , respectively. 


\section{Discussion}

This research attempted antilisterial protection of vegetables minimally processed by two-component mixtures of essential oils in sub-inhibitory concentrations with simultaneous good sensory evaluation of the product. The results indicate that SOO, SMO and $\mathrm{CO}$ had inhibitory effects on L. monocytogenes growth, but at different $\mathrm{MIC}$ values $(\mathrm{SOO}<\mathrm{CO}<\mathrm{SMO})$. The antibacterial activity of EOs depends on the phenolic components in which EOs are rich [24]. The SOO had the lowest MIC values, due to the highest percentage of carvacrol (79.11\%) [25]. Carvacrol is a phenolic compound that is credited with strong antibacterial properties. Cell death under the influence of carvacrol is the result of a rupture of the cytoplasmic membrane, which consequently leads to leakage of intracellular content [26]. CO and SMO had higher MIC values. Spanish marjoram oil is rich in 1,8-cineole $(69.15 \%)$, while in coriander oil, there is the most linalool (68.45\%). Previous studies have shown lower antilisterial activity of 1,8-cineole, linalool and $\alpha$-pinene than carvacrol and thymol [27-29]. The mechanism of action of monoterpenes found in EOs has also been described; among other things, it can disrupt the cellular respiration in bacteria [30].

Earlier studies suggest that a single treatment is usually not sufficient to ensure microbiological safety of fresh products $[29,31]$. Based on the FICI value, it was found that the mixtures of $\mathrm{SOO}+\mathrm{SMO}$ and $\mathrm{SOO}+\mathrm{CO}$ in a $1 / 4 \mathrm{MIC}+1 / 4 \mathrm{MIC}$ combination had synergistic antilisterial effects, which has not been reported before. In turn, the mixture of SMO + CO in a $1 / 4 \mathrm{MIC}+1 / 4 \mathrm{MIC}$ combination did not inhibit the growth of L. monocytogenes. The additive effect of this mixture was observed in a $1 / 4$ MIC + 1/2 MIC combination and was probably the result of summing the essential oils constituents with similar chemical structures. Mixtures of EOs in the other combinations had an additive or indifferent antilisterial effect. Similarly, a mixture of essential oils from Origanum vulgare L. and Rosmarinus officinalis L. and mixtures of O. vulgare with Thymus vulgaris (thyme) essential oils had a synergistic or additive effect on L. monocytogenes and other foodborne pathogens [32,33]. In earlier studies, a combined antilisterial effect between nisin and EOs was observed, and the addition of a third factor in the form of diglycerol monolaurate led to further combined antilisterial activities between the essential oil constituents and nisin even at lower, sub-lethal concentrations [29].

The L. monocytogenes suspension was then exposed to EOs in 1 MIC used alone and in combinations at $1 / 4$ MIC doses in the vegetable filtrate [32]. It turned out that in vegetable filtrate, EO mixtures at sub-inhibitory concentrations killed L. monocytogenes cells with the same effect as EOs alone at $1 \mathrm{MIC}$. At the same time intervals, a significantly greater $(p<0.05)$ reduction in L. monocytogenes was caused by the mixture of $\mathrm{SOO}+\mathrm{CO}$ than by $\mathrm{SOO}+\mathrm{SMO}$. This phenomenon can be explained by a greater synergy of ingredients in $\mathrm{SOO}+\mathrm{CO}$ compared to $\mathrm{SOO}+\mathrm{SMO}$. It is difficult to explain the synergy of the main components of EOs, because the antimicrobial activity of EOs consists of all components, even those found in very small amounts. In addition, the effectiveness of antibacterial activity can be enhanced by EO components with lipophilic properties, functional group strength and water solubility [32].

Nevertheless, it should be also noted that application EOs in fresh cut vegetables might be less effective than in vegetable filtrate. This can be explained by the worse contact of EOs with plant tissue due to unevenness and roughness of the surface, hydrophobicity and/or hydrophilicity and the presence of secondary antimicrobial metabolites in the composition of the surface [18,32].

The use of EOs to protect against the development of pathogens is only possible if such a product is accepted by consumers. The odor and taste of essential oils have been mostly determined by their chemical composition [24]. SOO with a high content of phenol monoterpenes, mainly carvacrol, had a sharp spicy flavor and taste, while SMO was distinguished by a pleasant, spicy odor and taste. CO displayed the worst characteristics, because it had a sweet, slightly spicy odor and a bitter taste. Mixtures of EOs in a $1 / 4$ MIC $+1 / 4$ MIC combination added to vegetables were in very low concentrations (SOO $0.0225 \%$, SMO $0.225 \%$ and $\mathrm{CO} 0.1 \%$ ). The better antilisterial, i.e., the $\mathrm{SOO}+\mathrm{CO}$ mixture, has poorer sensory characteristics than the $\mathrm{SOO}+\mathrm{SMO}$ mixture added to fresh vegetables. The odor and taste of SOO + SMO were minimally perceptible compared to the control, making vegetables with this mixture just as acceptable as vegetables without EOs. Similar results were obtained 
by Yamazaki et al. [29], where nisin and diglycerol monolaurate were used to enhance the antilisterial activity of essential oils. Such combinations allow for a reduction of the dosage of EO used in food preservation and thereby reduce the development of undesirable flavors in the final product.

\section{Conclusions}

Studies have shown that mixtures of EOs in sub-inhibitory concentrations inactivate L. monocytogenes in vegetable filtrate and in minimally processed vegetables. Optimal combinations of essential oils based on $\mathrm{SOO}+\mathrm{SMO}$ in low concentrations assist in achieving antilisterial activity in final products. Furthermore, such combinations of EOs do not affect the deterioration of odor and taste and maintain acceptable levels of sensory value.

Author Contributions: Conceptualization, K.K. and M.G.; methodology, K.K. and O.K.; formal analysis, O.K. and K.P.; investigation, K.K.; writing—original draft preparation, K.K.; writing—review and editing, K.K.; visualization, K.K.; supervision, M.G. All authors have read and agreed to the published version of the manuscript.

Funding: The work was co-financed by a statutory activity subsidy from the Polish Ministry of Science and Higher Education for the Institute of Food Sciences of Warsaw University of Life Sciences.

Conflicts of Interest: The authors declare no conflict of interest.

\section{References}

1. Zoellner, C.; Ceres, K.; Ghezzi-Kopel, K.; Wiedmann, M.; Ivanek, R. Design elements of Listeria environmental monitoring programs in food processing facilities: A scoping review of research and guidance materials. Compr. Rev. Food Sci. Food Saf. 2018, 17, 1156-1171. [CrossRef]

2. Olaimat, A.N.; Al-Holy, M.A.; Shahbaz, H.M.; Al-Nabulsi, A.A.; Abu Ghoush, M.H.; Osaili, T.M.; Ayyash, M.M.; Holley, R.A. Emergence of antibiotic resistance in Listeria monocytogenes isolated from food products: A comprehensive review. Compr. Rev. Food Sci. Food Saf. 2018, 17, 1277-1292. [CrossRef]

3. European Food Safety Authority and European Centre for Disease Prevention and Control (EFSA and ECDC). The European Union one health 2018 zoonoses report. EFSA J. 2019, 17, 5926. [CrossRef]

4. Oliveira, M.; Rodrigues, C.M.; Teixeira, P. Microbiological quality of raw berries and their products: A focus on foodborne pathogens. Heliyon 2019, 5, e02992. [CrossRef] [PubMed]

5. Rodríguez-López, P.; Rodríguez-Herrera, J.J.; Vázquez-Sánchez, D.; López Cabo, M. Current knowledge on Listeria monocytogenes biofilms in food-related environments: Incidence, resistance to biocides, ecology and biocontrol. Foods 2018, 7, 85. [CrossRef] [PubMed]

6. Carstens, C.K.; Salazar, J.K.; Darkoh, C. Multistate outbreaks of foodborne illness in the United States associated with fresh produce from 2010 to 2017. Front. Microbiol. 2019, 10, 2667. [CrossRef]

7. Buchanan, R.L.; Gorris, L.G.M.; Hayman, M.M.; Jackson, T.C.; Whiting, R.C. A review of Listeria monocytogenes: An update on outbreaks, virulence, dose-response, ecology, and risk assessments. Food Control 2017, 75, 1-13. [CrossRef]

8. Balali, G.I.; Yar, D.D.; Dela, V.G.A.; Adjei-Kusi, P. Microbial contamination, an increasing treat to the consumption of fresh fruits and vegetables in today's world. Int. J. Microbiol. 2020, 2020, 3029295. [CrossRef]

9. Tucci Tucci, P.; Centorotola, G.; Salini, R.; Iannetti, L.; Sperandii, F.; D’Alterio, N.; Migliorati, G.; Pomilio, F. Challenge test studies on Listeria monocytogenes in ready-to-eat iceberg lettuce. Food Sci. Nutr. 2019, 7, 3845-3852. [CrossRef]

10. Pignata, G.; Ertani, A.; Casale, M.; Piano, S.; Nicola, S. Mixing fresh-cut baby green and red leaf lettuce from soilless cultivation preserves phytochemical content and safety. Agric. Food Sci. 2020, 29, 55-65. [CrossRef]

11. Nousiainen, L.L.; Joutsen, S.; Lunden, J.; Hänninen, M.-L.; Fredriksson-Ahomaa, M. Bacterial quality and safety of packaged fresh leafy vegetables at the retail level in Finland. Int. J. Food Microbiol. 2016, 232, 73-79. [CrossRef] [PubMed]

12. Patrignani, F.; Siroli, L.; Serrazanetti, D.I.; Gardini, F.; Lanciotti, R. 2015. Innovative strategies based on the use of essential oils and their components to improve safety, shelf-life and quality of minimally processed fruits and vegetables. Trends Food Sci. Technol. 2015, 46, 311-319. [CrossRef] 
13. Kalemba, D.; Kunicka, A. Antibacterial and antifungal properties of essential oils. Curr. Med. Chem. 2003, 10, 813-829. [CrossRef] [PubMed]

14. Walker, J.F.; de Souza Santos, P.; Schmidt, C.A.; de Bittencourt, T.C.C.; Guimarães, A.G. Antimicrobial activity of marjoram (Origanum majorana) essential oil against the multidrug-resistant Salmonella enterica serovar Schwarzengrund inoculated in vegetables from organic farming. J. Food Saf. 2016, 36, 489-496. [CrossRef]

15. Todd, J.; Friedman, M.; Patel, J.; Jaroni, D.; Ravishankar, S. The antimicrobial effects of cinnamon leaf oil against multi-drug resistant Salmonella Newport on organic leafy greens. Int. J. Food Microbiol. 2013, 166, 193-199. [CrossRef]

16. Hyun, J.-E.; Bae, J.-M.; Song, H.; Yoon, J.-H.; Lee, S.-Y. Antibacterial effect of various essential oils against pathogens and spoilage microorganisms in fresh produce. J. Food Saf. 2015, 35, 206-219. [CrossRef]

17. Bouayad Alam, S.; Dib, M.E.A.; Djabou, N.; Tabti, B.; Gaouar Benyelles, N.; Costa, J.; Muselli, A. Essential oils as biocides for the control of fungal infections and devastating pest (Tuta absoluta) of tomato (Lycopersicon esculentum Mill.). Chem. Biodivers 2017, 14, e1700065. [CrossRef]

18. Ayala-Zavala, J.F.; Gonzáles-Aguilar, G.A.; del-Toro-Sánchez, L. Enhancing safety and aroma appealing of fresh-cut fruits and vegetables using the antimicrobial and aromatic power of essential oils. J. Food Sci. 2009, 74, R84-R91. [CrossRef]

19. Lv, F.; Liang, H.; Yuan, Q.; Li, C. In vitro antimicrobial effects and mechanism of action of selected plant essential oil combinations against four food-related microorganisms. Food Res. Int. 2011, 44, 3057-3064. [CrossRef]

20. Babushok, V.I.; Linstrom, P.J.; Zenkevich, I.G. Retention indices for frequently reported compounds of plant essential oils. J. Phys. Chem. Ref. Data 2011, 40, 043101. [CrossRef]

21. Doern, C.D. When Does 2 Plus 2 Equal 5? A Review of Antimicrobial Synergy Testing. J. Clin. Microbiol. 2014, 52, 4124-4128. [CrossRef] [PubMed]

22. Mota, A.P.P.; Campelo, T.A.; Frota, C.C. Evaluation of the antimicrobial activity Cinnamomum zeylanicum essential oil and trans-cinnamaldehyde against resistant Mycobacterium tuberculosis. Biosci. J. 2019, 35, 296-306. [CrossRef]

23. Baryłko-Pikielna, N.; Matuszewska, I. Sensoryczne Badania Żywności. Podstawy. Metody. Zastosowania, 2nd ed.; Wyd. Naukowe PTTŻ: Cracow, Poland, 2014.

24. Ibáñez, M.D.; Blázquez, M.A. Herbicidal value of essential oils from oregano-like flavour species. Food Agric. Immunol. 2017, 28, 1168-1180. [CrossRef]

25. Viuda-Martos, M.; Ruíz-Navajas, Y.; Fernández-López, J.; Pérez-Álvarez, J.A. Chemical composition of the essential oils obtained from some spices widely used in Mediterranean region. Acta Chim. Slov. 2007, 54, 921-926.

26. Kachur, K.; Suntres, Z. The antibacterial properties of phenolic isomers, carvacrol and thymol. Crit. Rev. Food Sci. Nutr. 2019, 60, 3042-3053. [CrossRef]

27. Tserennadmid, R.; Takó, M.; Galgóczy, L.; Papp, T.; Pesti, M.; Vágvölgyi, C.; Almássy, K.; Krisch, J. Anti yeast activities of some essential oils in growth medium, fruit juices and milk. Int. J. Food Microbiol. 2011, 144, 480-486. [CrossRef]

28. van Vuuren, S.F.; Viljoen, A.M. Antimicrobial activity of limonene enantiomers and 1,8-cineole alone and in combination. Flavour Fragr. J. 2007, 22, 540-544. [CrossRef]

29. Yamazaki, K.; Yamamoto, T.; Kawai, Y.; Inoue, N. Enhancement of antilisterial activity of essential oil constituents by nisin and diglycerol fatty acid ester. Food Microbiol. 2004, 21, 283-289. [CrossRef]

30. Deba, F.; Xuan, T.D.; Yasuda, M.; Tawata, S. Chemical composition and antioxidant, antibacterial and antifungal activities of the essential oils from Bidens pilosa Linn. var. radiata. Food Control 2008, 19, 346-352. [CrossRef]

31. Son, H.J.; Kang, J.H.; Song, K.B. Antimicrobial activity of safflower seed meal extract and its application as an antimicrobial agent for the inactivation of Listeria monocytogenes inoculated on fresh lettuce. LWT 2017, 85, 52-57. [CrossRef]

32. de Azeredo, G.A.; Stamford, T.L.M.; Nunes, P.C.; Neto, N.J.G.; de Oliveira, M.E.G.; de Souza, E.L. Combined application of essential oils from Origanum vulgare L. and Rosmarinus officinalis L. to inhibit bacteria and autochthonous microflora associated with minimally processed vegetables. Food Res. Int. 2011, 44, 1541-1548. [CrossRef] 
33. Gutierrez, J.; Bourke, P.; Lonchamp, J.; Barry-Ryan, C. Impact of plant essential oils on microbiological, organoleptic and quality parameters of minimally processed vegetables. Innov. Food Sci. Emerg. Technol. 2009, 10, 195-202. [CrossRef]

Publisher's Note: MDPI stays neutral with regard to jurisdictional claims in published maps and institutional affiliations.

(C) 2020 by the authors. Licensee MDPI, Basel, Switzerland. This article is an open access article distributed under the terms and conditions of the Creative Commons Attribution (CC BY) license (http://creativecommons.org/licenses/by/4.0/). 